\title{
Optimization of salt reduction and eggplant powder for chicken nugget formulation with white button mushroom as a meat extender
}

\author{
*Akesowan, A. and Jariyawaranugoon, U. \\ Department of Food Science and Technology, School of Science and Technology, University of the Thai \\ Chamber of Commerce, 126/1 Vibhavadee-Rangsit Road., Dindaeng, Bangkok 10400, Thailand
}

\begin{abstract}
Article history:
Received: 23 July 2020

Received in revised form: 20

August 2020

Accepted: 26 September 2020

Available Online: 10 January

2021
\end{abstract}

Keywords:

Eggplant powder,

Meat extender,

Nugget,

Salt reduction,

Response surface

methodology,

White button mushroom

DOI:

https://doi.org/10.26656/fr.2017.5(1).380

\section{Introduction}

In the last decades, most people worldwide have average sodium intake beyond the upper limit (recommended daily intake (RDI) for sodium is 2,300 $\mathrm{mg} /$ day) and lower fiber intake (RDI $=25-40 \mathrm{~g} /$ day) (WHO, 2016). Consequently, consumers suffer from food-related diseases, including high blood pressure, cardiovascular disease, kidney disease, osteoporosis, stroke, and colon cancer. Sodium chloride $(\mathrm{NaCl})$ is the most used ingredient to increase or enhance taste, flavor, and saltiness of the food products. It solubilizes myofibrillar proteins for fat and water binding capacity in meat batter (Chen et al. .).(2017 ,Many studies recommended for substituting $\mathrm{NaCl}$ with potassium chloride $(\mathrm{KCl})$, but most panelists found the bitter aftertaste in food products with $50 \% \mathrm{KCl}$ substitution or over. The flavor enhancer like monosodium glutamate and nucleotides could mask or reduce the bitterness in low-salt products. Still, it can cause some symptoms like headaches, sweating, and numbness in some sensitive people, in addition to a higher cost returns to manufacturers (Santos et al., 2014)

Several ingredients are investigated for resolving fiber deficiency in meat products, namely sorghum flour in gluten-free chicken nuggets (Devatkal et al., 2011), makgeolli lees in reduced-fat frankfurters (Choi et al., 2014), pea hull flour in low-fat chicken nuggets (Verma et al., 2015), and wheat bran and dried carrot pomace in chicken sausages (Yadav et al., 2018). In this study, mushroom and eggplant were of interest by their nutritional and functional properties. A white button mushroom (Agaricus bisporus) is a good source of protein, amino acids, carbohydrate, fiber $(12-14 \%$ dry weight), antioxidants, and phytochemicals, in addition to its significant amounts of vitamins and minerals particularly thiamine, riboflavin, potassium, magnesium, iron, and selenium. This mushroom is well known for its health benefits and therapeutic value. It can reduce cholesterol levels, prevent breast and prostate cancers, manage diabetes, promote the healthy gut system, and retard anti-aging development (Atila et al., 2017).

Eggplant fruit (Solanum melongena) is low in calories and sodium, but high in fiber (14-20\% dry weight), vitamins, and minerals, such as manganese, potassium, vitamin $\mathrm{C}$, and folate (Uthumporn et al., 2016). The eggplant flour also comprises large amounts of antioxidants, such as polyphenols (caffeic and chlorogenic acids), anthocyanins, and flavonoids. The consumption of eggplant is known to lower risks of heart 
disease, high blood pressure, cholesterol, obesity, tumor, and cancer, prevent memory loss and age-related macula degeneration, and improve the health of red blood cells. The high amounts of alpha-glucosidase and angiotensin compounds in eggplant are essential for glucose absorption control; hence, it usually uses in a diabetes diet (Gürbüz et al., 2018).

The partial meat replacement can provide several benefits, such as cost-saving, cholesterol and caloric value reduction, and dietary fiber fortification. The mushroom has gained popularity in use to enhance the meat-like texture, because of its water-binding capacity to increase yield and firmness. Additionally, it has an excellent flavor-enhancing property, showing a high potential to reduce sodium in meat products (Wong et al., 2019). Wan Rosli and Salihah (2012) reported that the addition of edible oyster mushrooms (Pleurotus sajor -caju) significantly made beef patties hard, cohesive, and chewy than their all-meat counterparts. While Wong et al. (2019) revealed the acceptable beef patties formulated with $27 \%$ salt reduction and $20 \%$ meat substitution with a white button mushroom. This suggests that the amount of salt would be too much when the recipe has reduced chicken meat content, proposing a strategy for salt reduction. Therefore, this study investigated the effect of salt reduction in the chicken nugget extended with white button mushroom while incorporating eggplant powder to develop the nugget quality using response surface methodology (RSM).

\section{Materials and methods}

\subsection{Materials}

Fresh white button mushroom and Thai long green eggplant were purchased from a local supermarket. Sodium tripolyphosphate (ACROS Organics, NJ, USA) and nugget ingredients such as chicken breast meat, sunflower oil, whole egg, chicken seasoning powder, salt, white pepper, white onion, and fresh garlic was used.

\subsection{Preparation of eggplant powder}

The eggplant was washed, peeled, transversely sliced ( $1 \mathrm{~cm}$ thickness), blanched in boiling water for $5 \mathrm{mins}$ and dried in a tray dryer at $55 \pm 2^{\circ} \mathrm{C}$ for $8 \mathrm{hrs}$. Then, the dried eggplant was ground for 3 mins and sifted through 50 mesh sieve.

\subsection{Chicken nugget processing}

Initially, fresh white button mushroom was washed, sliced into small size, and chopped using a food processor for $10 \mathrm{~s}$. The chicken nugget (a non-breaded style) formulation comprised $80 \%$ chicken breast meat/ white button mushroom (80:20), 5\% sunflower oil, 5\% whole egg, $5 \%$ water, $1.6 \%$ chopped white onion, $1.6 \%$ chopped garlic, $1 \%$ salt, $0.4 \%$ white pepper, $0.3 \%$ sodium tripolyphosphate, and $0.1 \%$ chicken seasoning powder. Chicken breast meat and white button mushroom were minced together for $10 \mathrm{~s}$ using a food processor. Sodium tripolyphosphate and previously prepared brine solution were added and mixed for $30 \mathrm{~s}$. Subsequently, remaining ingredients such as sunflower oil, whole egg, chopped white onion, chopped garlic, white pepper, and chicken seasoning powder were added and chopped for $1 \mathrm{~min}$. Raw nugget was manually shaped to a uniform size $\left(3 \times 1.1 \times 5 \mathrm{~cm}^{3}\right)$ and fried with palm oil at $150 \pm 2^{\circ} \mathrm{C}$ for 3 mins (internal temperature $\left.80 \pm^{\circ} 2 \mathrm{C}\right)$

\subsection{Experimental design}

Two independent variables, salt reduction $(0-40 \%$ on a salt weight basis) and eggplant powder $(0-5 \%$ on a total weight basis), were studied. A five-level combination coded $-1.41,-1,0,1,1.41$ containing thirteen experimental treatments were run using a central composite rotatable design (CCRD) (Table 1). The predictive model is proposed in the equation below:

where $\mathrm{Y}$ is the predictive response; $\mathrm{A}$ and $\mathrm{B}$ are the salt reduction and eggplant powder, respectively; $b_{0}$ is the intercept, $b_{1}$ and $b_{2}$ are linear, $b_{11}$ and $b_{22}$ are quadratic, and $b_{12}$ is the interaction coefficient, respectively.

$$
\mathrm{Y}=\mathrm{b}_{0}+\mathrm{b}_{1} \mathrm{~A}+\mathrm{b}_{2} \mathrm{~B}+\mathrm{b}_{11} \mathrm{~A}^{2}+\mathrm{b}_{22} \mathrm{~B}^{2}+\mathrm{b}_{12} \mathrm{AB}
$$

\subsection{Physical analysis}

\subsubsection{Cooking yield}

The weight of the nuggets was measured before and after cooking. The yield was reported as a percentage of the weight after cooking relative to the weight before cooking.

\subsubsection{Shrinkage}

The diameter of the raw batter and the cooked nugget was measured. The shrinkage was calculated as the percentage of the difference between raw and cooked nugget diameter.

\subsubsection{Firmness}

Each nugget was measured for the peak force $(\mathrm{N})$ using a Lloyd texture analyzer (LRX Plus, Lloyd Instruments, Hampshire, UK) equipped with a cutting test cell at a crosshead speed of $250 \mathrm{~mm} / \mathrm{min}$. Five samples per treatment were used for firmness measurement. 


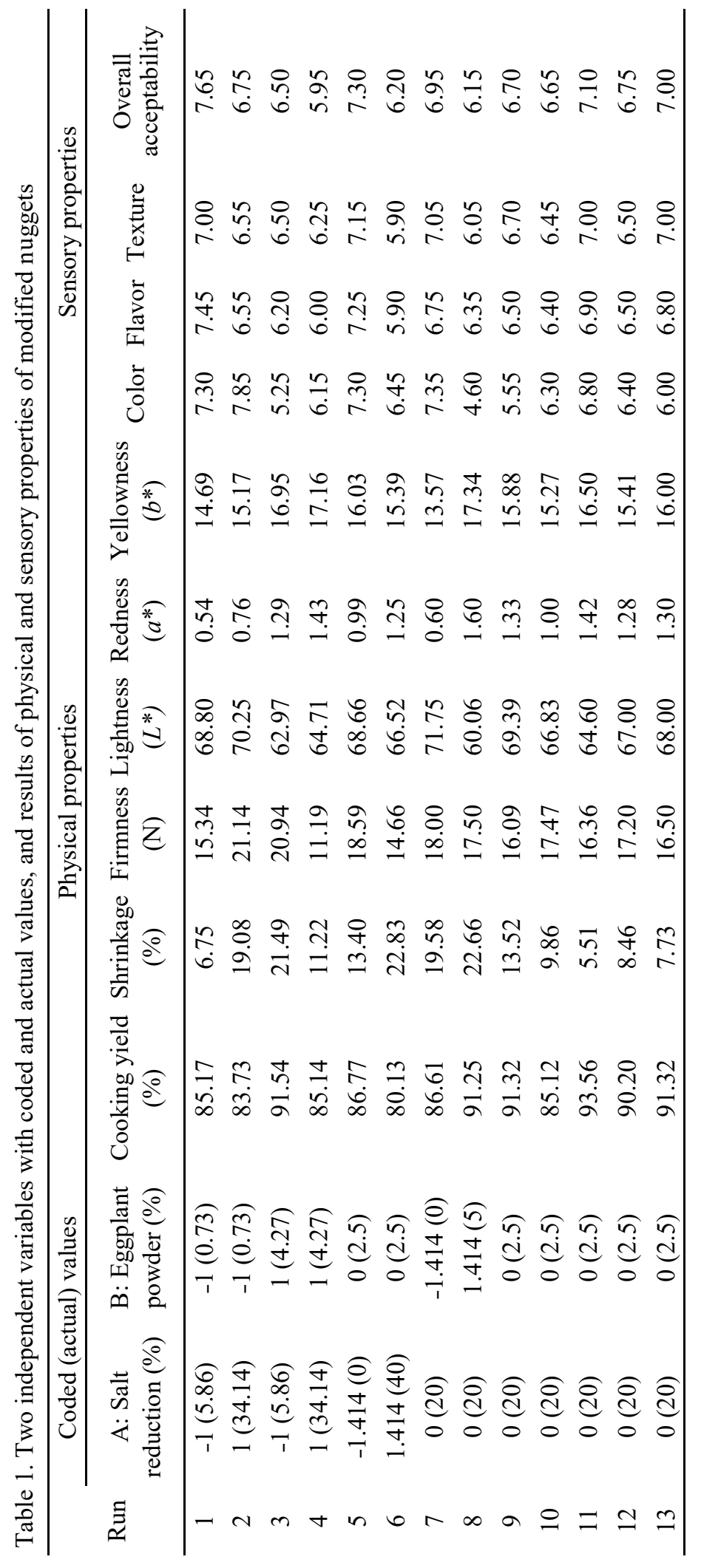




\subsubsection{Instrumental color}

The interior color of nuggets was determined using a colorimeter (MiniScan EZ, Hunter Associates Laboratory, Reston, VA) on the $L^{*} a^{*} b^{*}$ scales. Measurement was performed on five samples per treatment.

\subsection{Sensory evaluation}

The sensory test was performed using a 9-point hedonic scale ( 1 = extremely dislike, $9=$ extremely like) for evaluating tested attributes, including color, flavor, texture, and overall acceptability. Forty untrained panelists (aged between 18 and 55 years) who regularly consume nuggets were selected from the University of the Thai Chamber of Commerce in Thailand. Each panelist was instructed to rinse the palates before testing each sample, seated in an individual booth, and served with warmed samples (800 W, $45 \mathrm{~s}$ in a microwave) coded with random three-digit numbers.

\subsection{Statistical analysis}

All experiments were carried out with three replicates unless otherwise indicated. Data were analyzed by the Design-Expert ${ }^{\hat{\mathrm{a}}}$ Trial version 8.0.2 software (State-Ease Inc. ,Minneapolis, $\mathrm{MN}$ ) for analysis of variance (ANOVA), multiple regression, and optimization by RSM.

\section{Results and discussion}

\subsection{Statistical analysis and model fitting}

Results of the physical and sensory properties of the chicken/white button mushroom (80/20) nuggets with different levels of salt reduction (A) and eggplant powder (B) are given in Table 1. The fixed amount of salt used in this study was $1 \%(\mathrm{w} / \mathrm{w})$ based on the total weight. The highest salt reduction $(40 \%)$ in $\mathrm{T} 6$ showed the lowest cooking yield and highest shrinkage. The sample with $20 \%$ salt reduction and $2.5 \%$ eggplant powder (T11) presented the highest cooking yield and lowest shrinkage. At the higher salt reduction (34.14\%), T2 with $0.73 \%$ eggplant powder showed the highest firmness, while T4 with $4.27 \%$ eggplant powder showed the lowest. For color, T8, which contained the highest eggplant powder $(5 \%)$, presented the minimum $L^{*}$, and maximum $a^{*}$ and $b^{*}$ values compared to other formulations. Regarding sensory results, T1 containing salt reduction $(5.86 \%)$ and eggplant powder $(0.73 \%)$ was rated for the highest scores of flavor, texture, and overall acceptability. At the same time, the higher levels of eggplant powder appeared to lower sensorial characteristics.

Regression analysis and ANOVA results revealed that there were linear, quadratic, and interaction effects in the responses. With the confidence level having a $p$ value less than 0.05 , all physical and sensory models are described as given below.

$$
\begin{aligned}
& \text { Cooking yield }=90.30-2.15 \mathrm{~A}-3.38 \mathrm{~A}^{2} \\
& \left(\mathrm{R}^{2}=0.7873\right)
\end{aligned}
$$

Shrinkage $=9.02-5.65 \mathrm{AB}+3.30 \mathrm{~A}^{2}+4.81 \mathrm{~B}^{2}$ $\left(\mathrm{R}^{2}=0.7909\right)$

Firmness $=17.00-1.19 \mathrm{~A}-0.63 \mathrm{~B}-3.89 \mathrm{AB}$

$$
\left(\mathrm{R}^{2}=0.9348\right)
$$

$L^{*}=66.89-3.49 \mathrm{~B}\left(\mathrm{R}^{2}=0.8021\right)$

$a^{*}=1.14+0.35 \mathrm{~B}\left(\mathrm{R}^{2}=0.8059\right)$

$b^{*}=15.80+1.20 \mathrm{~B}\left(\mathrm{R}^{2}=0.8610\right)$

Color $=6.41-0.95 B\left(R^{2}=0.7087\right)$

Flavor $=6.58-0.38 \mathrm{~A}-0.30 \mathrm{~B}\left(\mathrm{R}^{2}=0.7546\right)$

Texture $=6.62-0.31 \mathrm{~A}-0.28 \mathrm{~B}\left(\mathrm{R}^{2}=0.7054\right)$

Overall acceptability $=6.74-0.38 \mathrm{~A}-0.38 \mathrm{~B}$

$$
\left(\mathrm{R}^{2}=0.8535\right)
$$

The coefficients of determination $\left(\mathrm{R}^{2}\right)$ values of physical responses ranged between 0.7873 and 0.9348 (Equations 2-7), and sensory responses ranged from 0.7054 to 0.8535 (Equations 8-11), all with nonsignificant lack of fit $(\mathrm{p}>0.05)$. These values, which are higher than 0.7 , indicate the reliability of the equations for changes of responses, and the models correlate well with the experimental values. The closer the $\mathrm{R}^{2}$ value to 1.0 shows, the model fits well with the actual data. Among all responses, the firmness model showed the highest $\mathrm{R}^{2}(0.9348)$, suggesting that it can explain $93.4 \%$ of the total sum of firmness changes, and this model cannot define only $6.6 \%$ of the total variability. To understand easily, results of physical and sensory responses were illustrating to three-dimensional graphs (Figure 1-2).

\subsection{Effect of salt reduction and eggplant powder on physical properties of chicken nuggets}

\subsubsection{Effect on cooking yield}

The predictive model indicated that the cooking yield ranged from 80.13 to $93.56 \%$ and significantly affected by the negative linear and quadratic effects of salt reduction (Figure 1a). At the same time, the eggplant powder and interaction effect of the two variables were negligible $(p>0.05)$. The result highlights the yield change mostly relates to the levels of salt content. In this study, the white button mushroom was used as a meat extender to keep moisture retention, enhance flavor, and modify meat texture in the chicken nugget. At a lower salt level, from 0 to $20 \%$ (Figure 1a), the cooking yield increased to a certain extent and decreased afterward. The finding indicates that the amount of salt used in the original chicken nugget might be unsuitable for processing the chicken/mushroom nugget formulation. 
(a)

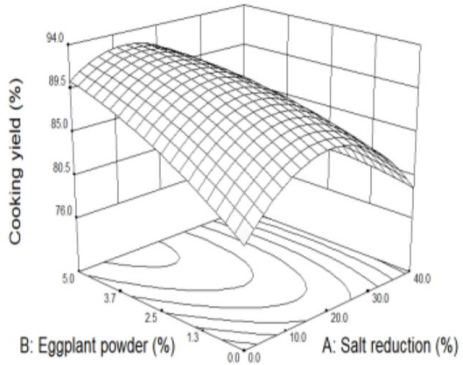

(d)

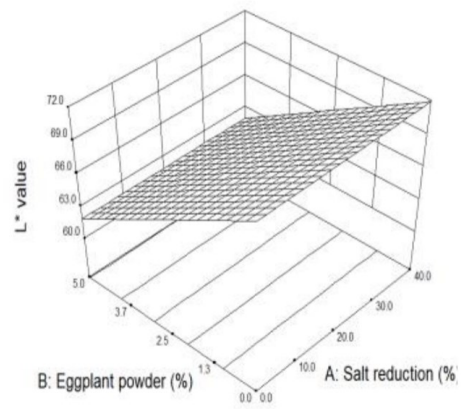

(b)

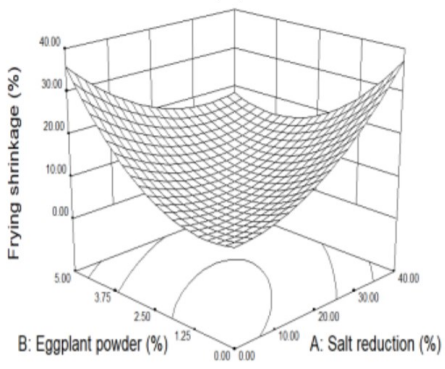

(e)

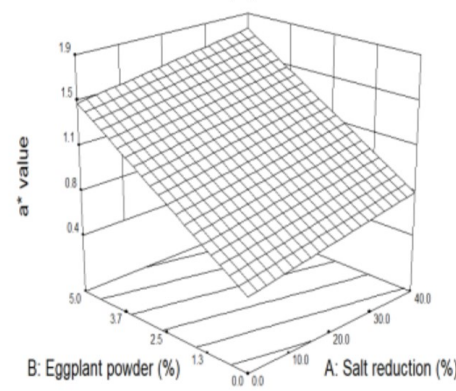

(c)

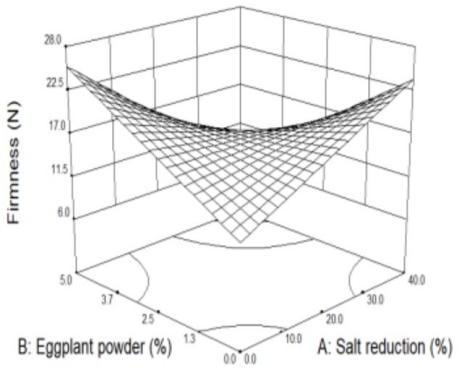

(f)

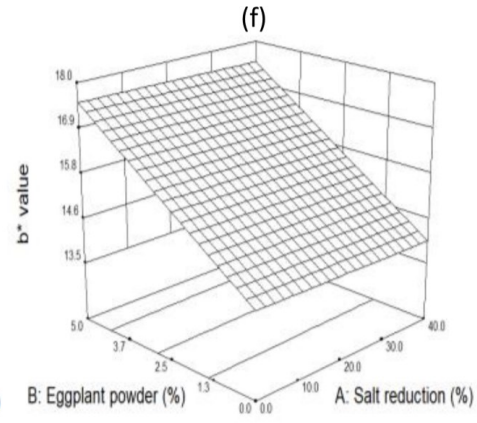

Figure 1. Physical properties of modified nuggets with salt reduction and eggplant powder: (a) cooking yield, (b) shrinkage, (c) firmness, (d) $L^{*}$ value, (e) $a^{*}$ value, and (f) $b^{*}$ value

(a)

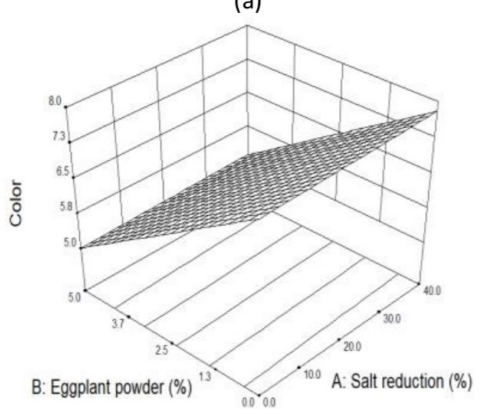

(c)

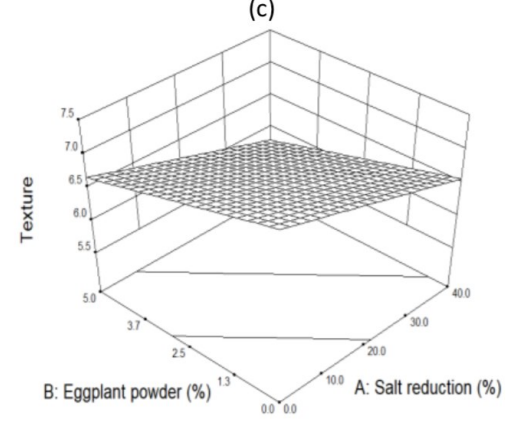

(b)

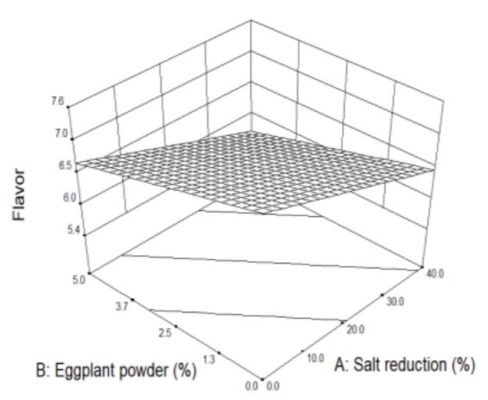

(d)

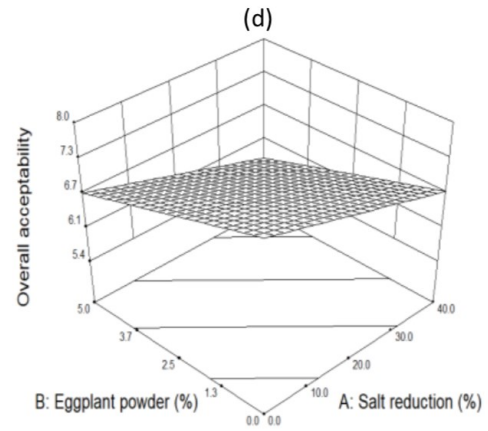

Figure 2. Sensory properties of modified nuggets with salt reduction and eggplant powder: (a) color, (b) flavor, (c) texture, and (d) overall acceptability

The excessive salt concentration, caused by the lowered chicken proportion, might remain in the meat batter. Higher dissolved sodium cations and chloride anions, which correspond to increasing the ionic strength, could affect the hydration and hydrophobic interactions of the soluble proteins. Pomeranz (1991) stated that, at high salt concentration, the higher adsorption of denatured sarcoplasmic proteins around the protein structure occurred. It subjected to disrupt entire myosin chains in the extracted protein, thus reducing the binding capacity of myosin and lowering cooking yield.

However, a much more salt reduction ( $>20$ to $40 \%$ ) decreased the cooking yield. The less salt content decreases the concentration of extracted protein, reflecting in a lower batter consistency that has reduced ability to hold water and fat globules in meat mixture (Asgar et al., 2010). Additionally, the lower waterbinding power of myosin between meat particles might weaken the protein-protein gel/emulsion matrix, causing a less competent to hold the water molecules during cooking (Yogesh et al., 2013). The finding was confirmed by the work of Wang et al. (2010), revealing that the relationship between volumetric shrinkage and moisture loss of chicken nuggets during deep-fat frying 
was almost linear.

\subsubsection{Effect on shrinkage}

The shrinkage, which ranges from 5.51 to $22.83 \%$, was influenced by the positive quadratic effects of salt reduction and eggplant powder, and the negative interaction term of these variables (Figure 1b). The variable most affecting the shrinkage response is the eggplant powder having the highest $\mathrm{B}^{2}$ coefficient at 4.81 (Equation 3). Generally, the nugget will undergo considerable shrinkage during frying, possibly because of several factors such as initial moisture content, constituents, volume reduction by moisture loss, pores change, and protein denaturation (Wang et al., 2010). Figure $1 \mathrm{~b}$ shows a higher shrinkage with increasing levels of salt reduction or eggplant powder. A high salt reduction $(30-40 \%)$ caused a lower water-binding capacity batter, contributing to high moisture loss. Higher eggplant powder (3.5-5\%), contained a high total dietary fiber (42-45\%), might compete for water against the extracted protein (Uthumporn et al., 2016). It was in line with Verma et al. (2012), who displayed that the high water-binding capacity in the meat system resulted in higher cooking yield and lower shrinkage.

The shrinkage decreased by the negative interaction terms of these variables (Equation 3). Generally, when the types and amounts of nugget compositions are changed or reformulated, the shrinkage may increase or decrease. The modified nugget, which has a similar shrinkage to the traditional sample, will be a good alternative. According to Figure 1b, when using low levels of salt reduction $(<15 \%)$ and eggplant powder $(<2.5 \%)$, the obtained shrinkage was somewhat similar to the regular formulation. It is presumably because the interaction of water and eggplant fiber through hydrogen bonding might hinder the displacement of water by oil during frying (Kim et al., 2015). The addition of proper eggplant powder is in line with increasing sufficient eggplant molecules to fill the pores around the protein gel matrix. A dense protein structure formed could maintain its shape and retain water inside during frying, leading to decreasing a nugget size (Lee and Chin, 2019).

\subsubsection{Effect on the firmness}

As shown in Figure 1c, the lowest firmness was observed at $11.19 \mathrm{~N}$, while the highest was $21.14 \mathrm{~N}$. The negative linear terms of salt reduction and eggplant powder, and their interactions affected the firmness. The eggplant powder showed a more significant effect on the firmness. As seen in Figure $1 b-c$, the variation of firmness appeared to correspond with the shrinkage surface curve. A more shrinkage presented a tough and hard texture nugget influenced by high levels of salt reduction $(30-40 \%)$ or eggplant powder $(4-5 \%)$. A gentle, firm, and tender nugget, which is the right texture, was achieved by low levels of salt reduction $(<10 \%)$ and eggplant powder $(<3 \%)$. The amount of protein content and extenders, types and levels of nonmeat ingredients, degree of comminution, and ingredient compatibility play a decisive role in the nugget firmness. It was consistent with Yadav et al. (2018), who demonstrated a firmer texture of chicken nuggets, because of high water-holding capacity by added wheat bran and dried carrot pomace. Carvalho et al. (2017) reported that collagen and textured soy protein/collagen blend significantly increased the hardness of beef burgers when incorporating.

\subsubsection{Effect on the instrumental color}

Changes in interior color parameters of the modified nuggets, namely $L^{*}(60.06-71.75), a^{*}(0.60-1.60)$, and $b^{*}(13.57-17.34)$ are presented in Figure 1d-f. The addition of eggplant powder showed a negative linear effect on $L^{*}$ but positively affected on $a^{*}$ and $b^{*}$ (Equation 5-7), while the salt reduction was comparable $(p>0.05)$. There was no interaction effect of the two variables. The addition of eggplant powder makes the nugget darker and more intensely red and yellow. It is because of the color of eggplant powder (light brown), the change in color of mushroom flesh from white to brown after processing, reduced heme-pigment, and change in constituents.

\subsubsection{Effect of salt reduction and eggplant powder on sensory evaluation of chicken nuggets}

Color, flavor, texture, and overall acceptability were rated 4.60-7.85, 6.00-7.45, 5.90-7.10, and 6.20-7.65, respectively (Figure 2a-d). The two independent variables showed significant effects on all sensory responses, except for the response of color, which only affected by eggplant powder. No interaction effects were found in all responses. As seen in Figure 2a, the impact of salt reduction was negligible, while the eggplant powder lowered the color score. It was confirmed by the lowest $L^{*}$ measured in the T8 with the highest $5 \%$ eggplant powder (Table 1). The finding implies that most panelists are not appreciated darker nugget color. Comparatively, the salt reduction showed a greater effect on both flavor and texture than that with eggplant powder. The lower salt content resulted in reducing the saltiness intensity in nuggets, which affected the panelists' liking (Figure 2b). The impact of individual consumer reaction, perceived saltiness pleasantness, taste -flavor interactions, and sodium release rate might be noted for this observation (Hoppu et al., 2017). A unique flavor and sweet style of the eggplant powder might 
interfere with the nugget flavor. At the same time, the high hydrated eggplant powder and white button mushroom could cut down the intensity of the protein part, subjecting to reduce the umami substances such as glutamate and 5'nucleotides. It also affects the flavor developing reaction through the Maillard browning between amino acids and reducing sugars. In this regard, the nuggets become less palatable by decreasing the meaty flavor (Dermiki et al., 2013). Figure 2c shows that, at higher levels of both salt reduction and eggplant powder, the modified nugget rather presented a meat-like or meat imitation texture. A process of such a modified nugget is broken down in the mouth might be unfamiliar to the panelists, and dissatisfies their preference, thereby it received the lower texture score.

The overall acceptability rating was influenced by flavor and texture perception, as shown in Table 1. It can observe similar shapes of surface curves among these attributes (Figure 2b-d). When considering the recommended overall acceptability, at a salt reduction $(<10 \%)$ and eggplant powder $(<2.5 \%)$, it will obtain the nugget with a "like moderately" level. However, at high levels of salt reduction (40\%) and eggplant powder (5\%), it induced a decrease in the "indifferent" level.

\subsection{Optimization and validation}

The criteria of responses used for the numerical optimization are cooking yield, shrinkage, firmness, and overall acceptability. The optimal condition (desirability $=0.74$ ) was achieved using $12.94 \%$ salt reduction and $2.73 \%$ eggplant powder. The predicted values for cooking yield, shrinkage, firmness, and overall acceptability were $90.84 \%, 9.50 \%, 17.76 \mathrm{~N}$, and 6.88 , respectively. While the experimental values $(n=3)$ for cooking yield, shrinkage, firmness, and overall acceptability of the nuggets $(\mathrm{n}=3)$ were $92.65 \%$, $10.22 \%, 18.85 \mathrm{~N}$, and 6.96, which displayed a percentage of relative error of $1.99,7.58,6.14$, and $1.16 \%$, respectively. The result ensures that the predicted model of the nugget is feasible and effective.

\section{Conclusion}

The amount of salt could be reduced in the chicken nugget extended with $20 \%$ white button mushroom. While the eggplant powder might amend and improve the physical properties. The low levels of salt reduction and eggplant powder could enhance cooking yield, shrinkage, and firmness, but affect the chromatic color in the modified nugget. However, the high levels of the two variables deteriorated the nugget quality. The optimal condition was established as reducing $12.94 \%$ salt content and incorporating $2.73 \%$ eggplant powder.

\section{Conflict of interest}

The authors declare no conflict of interest

\section{Acknowledgments}

The authors thank the University of the Thai Chamber of Commerce for supporting this study.

\section{References}

Asgar, M.A., Fazilah, A., Huda, N., Bhat, R. and Karim, A.A. (2010). Nonmeat protein alternatives as meat extenders and meat analogs. Comprehensive Reviews in Food Science and Food Safety, 9(5), 513-529. https://doi.org/10.1111/j.1541-4337.2010.00124.x

Atila, F., Owaid, M.N. and Shariati, M.A. (2017). The nutritional and medical benefits of Agaricus bisporus: A review. Journal of Microbiology, Biotechnology and Food Sciences, 7, 281-286. https://doi.org/10.15414/jmbfs.2017/18.7.3.281-286

Carvalho, G.R., Milani, T.M.G., Trinca, M.R.R., Naiga, L.Y. and Barreto, A.C.S. (2017). Textured soy protein, collagen and maltodextrin as extenders to improve the physicochemical and sensory properties of beef burger. Food Science and Technology, 37 (Suppl. 1), 10-16. https://doi.org/10.1590/1678$457 x .31916$

Chen, X., Tume, R.K., Xu, X. and Guanghong, Z. (2017). Solubilization of myofibrillar proteins in water or low ionic strength media: Classical techniques, basic principals and novel functionalities. Critical Reviews in Food Science and Nutrition, 57(15), 3260-3280. https://doi.org/10.1080/10408398.2015.1110111

Choi, Y.S., Kim, H.W., Hwang, K.E., Song, D.H., Choi, J.H., Lee, M.A., Chung, H.J. and Kim, C.J. (2014). Physicochemical properties and sensory characteristics of reduced-fat frankfurters with pork back fat replaced by dietary fiber extracted from makgeolli lees. Meat Science, 96(2), 892-900. https://doi.org/10.1016/j.meatsci.2013.08.033

Dermiki, M., Mounayar, R. ,Suwankanit, C. ,Scott, J., Kennedy, O.B. ,Mottram, D.S. ,Gosney, M.A., Blumenthal, H. and Methven, L.(2013) . Maximising umami taste in meat using natural ingredients: Effects on chemistry, sensory perception and hedonic liking in young and old consumers. Journal of the Science of Food and Agriculture, 93(13), 3312 -3321. https://doi.org/10.1002/jsfa.6177

Devatkal, S.K., Kadam, D.M., Naik, P.K. and Sahoo, J. (2011). Quality characteristics of gluten-free chicken nuggets extended with sorghum flour. Journal of Food Quality, 34(2), 88-92. https://doi.org/10.1111/ 


\section{j.1745-4557.2010.00367.x}

Gürbüz, N., Uluisşik, S., Frary, A., Frary, A. and Doğanlar, S. (2018). Health benefits and bioactive compounds of eggplant. Food Chemistry, 268, 602610. https://doi.org/10.1016/j.foodchem.2018.06.093

Kim, H.Y., Kim, K.J., Lee, J.W., Kim, G.W., Choe, J.H., Kim, H.W., Yoon, Y. and Kim, C.J. (2015). Quality evaluation of chicken nugget formulated with various contents of chicken skin and wheat fiber mixture. Korean Journal for Food Science of Animal Resources, 35(1), 19-.26 https://doi.org/10.5851/ kosfa.2015.35.1.19

Lee, C.H. and Chin, K.B. (2019). Evaluation of physicochemical and textural properties of myofibrillar protein gels and low-fat model sausage containing various levels of curdlan. AsianAustralasian Journal of animal Sciences, 32(1), 144-151. https://doi.org/10.5713/ajas.18.0585

Pomeranz, Y. (1991). Functional Properties of Food Components. $2^{\text {nd }}$ ed. New York: Academic Press.

Santos, B.A. ,Campagnol, P.C.B. ,Morgano, M.A. and Pollonio, M.A.R.(2014) . Monosodium glutamate, disodium inosinate, disodium guanylate, lysine and taurine improve the sensory quality of fermented cooked sausages with $50 \%$ and $75 \%$ replacement of $\mathrm{NaCl}$ with KCl. Meat Science, 96(1), 509-513. https://doi.org/10.1016/j.meatsci.2013.08.024

Uthumporn, U., Fazilah, A., Tajul, A.Y., Maizura, M. and Ruri, A.S. (2016). Physico-chemical and antioxidant properties of eggplant flour as a functional ingredient. Advance Journal of Food Science and Technology, 12(5), 235-243. https:// doi.org/10.19026/ajfst.12.2905

Verma, A.K., Sharma, B.D. and Banerjee, R. (2012). Quality characteristics of low-fat chicken nuggets: Effect of common salt replacement and added bottle gourd )Lagenaria siceraria L.). Journal of the Science of Food and Agriculture, 92(9), 1848-1854. https://doi.org/10.1002/jsfa.5691

Verma, A.K., Banerjee, R. and Sharma, B.D. (2015). Quality characteristics of low-fat chicken nuggets: Effect of salt substitute blend and pea hull flour. Journal of Food Science and Technology, 52, 2288$.2295 \mathrm{https} / / /$ doi.org/10.1007/s13197-013-1218-1

Wan Rosli, W.I. and Solihah, M.A. (2012). Effect on the addition of Pleurotus sajor-caju (PSC) on physical and sensorial properties of beef patty. International Food Research Journal, 19(3), 993-999.

Wang, Y., Ngadi, M.O. and Adedeji, A.A. (2010). Shrinkage of chicken nuggets during deep-fat frying. International Journal of Food Properties, 13(2), 404 -410. https://doi.org/10.1080/10942910802626721
Wong, K.S., Corradini, M.G., Auto, W. and Kinchla, A.J. (2019). Sodium reduction strategies through use of meat extenders (white button mushrooms VS. textured soy) in beef patties. Food Science and Nutrition, 7(2), 506-.518 https://doi.org/10.1002/ fsn3.824

World Health Organization (WHO). (2016). Salt reduction. Retrieved on June 30, 2019 from WHO website: https://www.who.int/news-room/factsheets/detail/salt-reduction

Yadav, S., Pathera, A.K., Islam, R.U., Alik, A.K. and Sharma, D.P. (2018). Effect of wheat bran and dried carrot pomace addition on quality characteristics of chicken sausage. Asian-Australasian Journal of animal Sciences, 31(5), 729-737. https:// doi.org/10.5713/ajas.17.0214

Yogesh, K., Ahmad, T., Manpreet, G., Mangesh, K. and Das, P. (2013). Characteristics of chicken nuggets as affected by added fat and variable salt contents. Journal of Food Science and Technology, 50, 191196. https://doi.org/10.1007/s13197-012-0617-z 